\title{
BINDING OF ERYTHROMYCIN TO ESCHERICHIA COLI RIBOSOMES
}

\author{
Hiroshi TERAOKA \\ Shionogi Research Laboratory, Shionogi \& Co., Ltd., \\ Fukushima-ku, Osaka, Japan
}

(Received for publication February 22, 1971)

\begin{abstract}
This paper concerns a precise study on the nature of the binding of erythromycin to Escherichia coli (Q13) ribosomes. (1) An equimolar amount of erythromycin bound to $50 \mathrm{~S}$ ribosomal subunits at extremely low concentrations and this binding was not affected by the addition of $30 \mathrm{~S}$ ribosomal subunits. (2) The binding of erythromycin to ribosomes was not significantly influenced by decreasing the $\mathrm{Mg}^{++}$concentration to $10^{-4} \mathrm{M}$, although it was dependent upon the concentration of $\mathrm{K}^{+}$or $\mathrm{NH}_{4}^{+}$as previously reported. Other components required for protein synthesis showed little effect on the binding. (3) Washing the ribosomes with $\mathrm{NH}_{4} \mathrm{Cl}$ did not influence their erythromycin-binding capacity or their dependence on $\mathrm{K}^{+}$or $\mathrm{NH}_{4}{ }^{+}$. The addition of $\mathrm{Li}^{+}$caused a remarkable inhibition of the antibiotic binding and this inhibition was reversed by the concomitant addition of $\mathrm{NH}_{4}{ }^{+}$. (4) The erythromycin-binding ability of ribosomes from Bacillus subtilis, gram-positive bacteria, was roughly the same as that of those from gram-negative $E$. coli. In contrast to bacterial ribosomes, rabbit reticulocyte ribosomes bound erythromycin hardly at all.
\end{abstract}

In the earlier papers from this laboratory it was reported that erythromycin binds to Escherichia coli ribosomes and that this binding resulted in a characteristic change in the ability of ribosomes for poly $A$ dependent polylysine synthesis ${ }^{1,2}$. This was confirmed by the isolation of ${ }^{14} \mathrm{C}$-erythromycin bound ribosomes by Sephadex column chromatography ${ }^{3)}$ and by adsorption on Millipore filter ${ }^{4)}$. The binding of this antibiotic was also confirmed with ribosome preparations from gram-positive bacteria such as Bacillus subtilis ${ }^{5)}$ and Staphylococcus aureus ${ }^{6}$. TAUBMAN et al. ${ }^{5)}$ revealed that erythromycin binds exclusively to $50 \mathrm{~S}$ ribosomal subunits of B. subtilis, a subunit specificity likewise observed for $S$. aureus ribosomes ${ }^{6)}$ and for $E$. coli ${ }^{7}$. We have previously reported the essential requirement of monovalent cations, such as $\mathrm{K}^{+}$or $\mathrm{NH}_{4}^{+}$, for the binding of erythromycin to $E$. coli ribosomes ${ }^{8)}$ as shown also for ribosomes from B. subtilis ${ }^{9)}$ and $S$. aureus ${ }^{10)}$. Furthermore, a recent study in this laboratory suggested that the binding affinity of $E$. coli ribosomes for erythromycin depends upon the ribosome conformation which is reversibly altered with changes in the concentration of $\mathrm{K}^{+}$or $\mathrm{NH}_{4}^{+}$, the rate of the alteration being largely dependent upon temperature ${ }^{11}$.

In this report, further investigations on the binding of erythromycin to ribosomes are presented and the results are consistent with our previous notion that the ability 
of ribosomes to bind erythromycin is dependent upon the ribosome conformation.

\section{Materials and Methods}

Ribosomes were prepared according to the method of NiREnBerg ${ }^{12)}$ from E. coli Q13, E. coli QE 201 (erythromycin-resistant mutant derived from Q13 as described previously $\left.{ }^{13}\right)$ ) and $B$. subtilis (PCI 219) respectively. Rabbit reticulocyte ribosomes were prepared as described in the previous paper ${ }^{14)}$ : $105,000 \times g$ supernatant fraction $(\mathrm{S}-100)$ and tRNA were obtained from $E$. coli Q13 as described in the previous paper ${ }^{2)}$. The $30 \mathrm{~S}$ and $50 \mathrm{~S}$ subunits of the ribosomes were prepared by sucrose gradient centrifugation after dissociation by the addition of phosphate ${ }^{15)} \cdot{ }^{14} \mathrm{C}$-Erythromycin was prepared by short term incubation of washed mycelium of Streptomyces erythreus with $1{ }^{-14} \mathrm{C}$-propionate according to KANEDA et al. ${ }^{16)}$ Paper chromatographic analysis of this preparation showed that approximately $87 \%, 4 \%$ and $9 \%$ of total radioactivity was found in the spots of erythromycin A, B and C, respectively. Antimicrobial assay employing B. subtilis (PCI 219) showed that the radioactive preparation which corresponded to approximately $0.61 \mu \mathrm{g}$ of erythromycin A gave 13,000 cpm under the experimental conditions described below.

Poly A and GTP were obtained from Sigma Co. ATP was purchased from Schwarz BioResearch Inc. Phosphoenolpyruvate and pyruvate kinase were obtained from C. F. Boehringer \& Soehne GmbH.

The binding of erythromycin to ribosomes was measured by the adsorption of the binding-complex on Millipore filter ${ }^{4}$. The reaction mixture contained ribosomes $(2.8 \sim 4.0$ $\mathrm{A}_{260}$ units as indicated in respective legends), $2,700 \mathrm{cpm}$ of ${ }^{14} \mathrm{C}$-erythromycin (175 $\mu \mu \mathrm{moles}$ ), $50 \mathrm{~mm}$ Tris- $\mathrm{HCl}(\mathrm{pH} 7.8), 16 \mathrm{mM}$ magnesium acetate and $70 \mathrm{mM} \mathrm{KCl}$ in a final volume of $125 \mu$. The reaction mixture was incubated at $37^{\circ} \mathrm{C}$ for 15 minutes unless otherwise specified. After incubation, the reaction tube was immediately immersed in an ice bath and the reaction mixture diluted with $5 \mathrm{ml}$ of cold buffer containing $0.025 \mathrm{M}$ Tris- $\mathrm{HCl}$ $(\mathrm{pH} 7.8), 0.06 \mathrm{M} \mathrm{KCl}$ and $0.02 \mathrm{M}$ magnesium acetate. This diluted mixture was poured onto a Millipore filter (HA, $0.45 \mu$, pre-washed with the same buffer) and the filter was washed 5 times with $3-\mathrm{ml}$ portions of the cold buffer. No detectable amount of erythromycin was liberated from the erythromycin-ribosome complex during the washing process. The bound ${ }^{14} \mathrm{C}$-erythromycin on the filter was counted with a Beckman liquid scintillation counting system using conventional toluene scintillation solution. Under these assay conditions, adsorption of the ribosomes on the Millipore filter was not affected by addition or omission of the various components in the reaction mixture described above.

\section{Results}

(1) Stoichiometric Binding of Erythromycin to E. coli Ribosomes

As shown in Fig. 1, a linear relationship was observed between the amount of ribosomes and the total count of ${ }^{14} \mathrm{C}$-erythromycin bound to the ribosomes at sufficient concentration of ${ }^{14} \mathrm{C}$-erythromycin.

As shown in Table 1 , the specific activity of the ${ }^{14} \mathrm{C}$-erythromycin-ribosome complex decreased proportionally on making increasing additions of nonlabeled erythromycin $\mathrm{A}$ to the incubation mixture containing fixed amounts of ribosomes and ${ }^{14} \mathrm{C}-$ erythromycin. On the basis of these observation, it may safely be assumed that the same amount of erythromycin is bound to a fixed quantity of ribosomes throughout the range of erythromycin concentration employed, and so the specific activity of the original preparation of ${ }^{14} \mathrm{C}$-erythromycin could be calculated from combinations of the experimental data on the radioactivities bound to the ribosomes and the amounts of nonlabeled erythromycin added. The values obtained from the possible combina- 
Fig. 1. The binding of erythromycin to ribosomes.

Incubation mixture contained the components described under "Materials and Methods" except that indicated amounts of ribosomes and $875 \mu \mu$ moles of ${ }^{14} \mathrm{C}$-erythromycin $(13,500 \mathrm{cpm})$ were added.

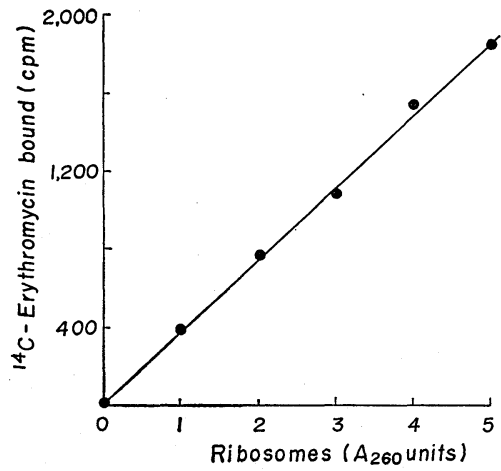

Fig. 2. Effect of erythromycin concentration on the binding of erythromycin to ribosomes.

Incubation mixture contained $3.0 \mathrm{~A}_{260}$ units of ribosomes and the components described under "Materials and Methods" except that indicated amounts of ${ }^{14} \mathrm{C}$-erythromycin were added.

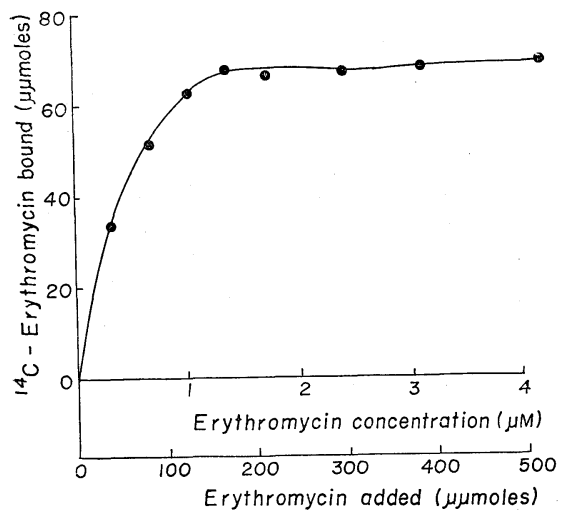

Table 1. Effect of the addition of non-radioactive erythromycin $A$ on the specific activity of ${ }^{14} \mathrm{C}$-erythromycin-ribosome complex

\begin{tabular}{c|c}
\hline $\begin{array}{c}{ }^{12} \text { C-Erythromycin added } \\
(\mu \mu \text { moles })\end{array}$ & $\begin{array}{c}{ }^{14} \text { C-Erythromycin bound } \\
(\mathrm{cpm})\end{array}$ \\
\hline 0 & 950 \\
100 & 607 \\
200 & 435 \\
400 & 293 \\
800 & 166
\end{tabular}

Incubation mixture contained $2.8 \mathrm{~A}_{260}$ units of ribosomes and indicated amounts of ${ }^{12} \mathrm{C}$-erythromycin $\mathrm{A}$ in addition to the components described under "Materials and Methods".

Table 2. Effect of $30 \mathrm{~S}$ subunits on the binding of erythromycin to $50 \mathrm{~S}$ subunits

\begin{tabular}{cc|c|c}
\hline \multicolumn{2}{c|}{$\begin{array}{c}\text { Ribosomal subunits added } \\
\left(A_{260} \text { unit }\right)\end{array}$} & \multicolumn{2}{|c}{${ }^{14}$ C-Erythromycin bound } \\
\cline { 2 - 3 } & cpm & $\mu \mu$ mole \\
\hline $30 \mathrm{~S}$ & $(1.0)$ & 1 & 0.1 \\
$50 \mathrm{~S}$ & $(1.0)$ & 949 & 29.1 \\
$50 \mathrm{~S}$ & $(2.0)$ & 499 & 64.2 \\
$30 \mathrm{~S}(1.0)+50 \mathrm{~S}(1.0)$ & 998 & 32.4 \\
$30 \mathrm{~S}(1.0)+50 \mathrm{~S}(2.0)$ & 64.8 \\
\hline
\end{tabular}

Incubation mixture contained the components described under "Materials and Methods" except that indicated amounts of $30 \mathrm{~S}$ and $50 \mathrm{~S}$ ribosomal subunits were used in place of $70 \mathrm{~S}$ ribosomes.

tions of experimental data were very close to each other. Their average was $2,700 \mathrm{cpm}$ per $175 \mu \mu$ moles, a value which agreed very well with that obtained from microbiological assay in which $2,700 \mathrm{cpm}$ of ${ }^{14} \mathrm{C}$-erythromycin corresponded to $166 \mu \mu$ moles of erythromycin A. Throughout this paper the amount of ${ }^{14} \mathrm{C}$-erythromycin was calculated using a specific activity of $2,700 \mathrm{cpm}$ per $175 \mu \mu$ moles.

As shown in Fig. 2, the amount of erythromycin bound to a fixed amount of ribosomes reached a maximum at a very low concentration of antibiotic and no detectable increase was observed with further increment in the antibiotic concentration. If one $\mathrm{A}_{260}$ unit of $70 \mathrm{~S}$ ribosomes of $E$. coli corresponds to approximately 25 $\mu \mu$ moles as shown by Tissieres et $a l .{ }^{15)}$, then the result obtained in this experiment is consistent with the previous observation that approximately one molecule of erythromycin binds to a ribosome from B. subtilis ${ }^{17)}$ or $S$. aureus ${ }^{6)}$ at low concentration of the antibiotic.

As is evident from Fig. 2, the addition of $75 \mu \mu$ moles erythromycin, which is approximate equimolar to ribosomes in the reaction mixture, caused the formation of as much as $50 \mu \mu$ moles erythromycin-ribosome complex. This fact indicates that $E$. coli ribosomes have very high affinity for the antibiotic. 
Table 2 shows that a $50 \mathrm{~S}$ ribosomal subunit could bind one molecule of erythromycin as has been observed for $70 \mathrm{~S}$ ribosomes. The $30 \mathrm{~S}$ subunits bound no detectable amount of the antibiotic and the addition of $30 \mathrm{~S}$ subunits did not affect the binding of erythromycin to $50 \mathrm{~S}$ subunits.

(2) Effects of the Components Required for Polypeptide Synthesis on the Binding of Erythromycin to Ribosomes

In an attempt to detect the effects of components in poly A directed polylysine synthesizing system on the binding of erythromycin to ribosomes, S-100, poly A, ATP, phosphoenolpyruvate, pyruvate kinase, GTP, and 2-mercaptoethanol were added to the binding reaction mixture. As shown in Table 3, the addition of these components showed no detectable effect on this binding.

(3) The Time Course of the Binding of Erythromycin to Ribosomes

The rate of binding of erythromycin was studied at three different temperatures (Fig. 3). As expected from the previous paper ${ }^{11)}$, at $37^{\circ} \mathrm{C}$ the maximum binding was observed within approximately 5 minutes of incubation. At $25^{\circ} \mathrm{C}$, however, much longer incubation was needed for the maximum binding of the antibiotic. At $0^{\circ} \mathrm{C}$, a significant but small amount of the antibiotic was bound to ribosomes even after 15 minutes incubation.

\section{(4) Influence of $\mathrm{pH}$}

The amount of erythromycin bound to the ribosomes remained essentially constant at pHs between 7.0 and 8.0.

(5) Effect of $\mathrm{Mg}^{++}$Concentration

The ability of ribosomes to bind erythromycin was not significantly altered by decreasing the concentration of $\mathrm{Mg}^{++}$to $10^{-4} \mathrm{M}$ or by the addition of phosphate, which induces dissociation of $70 \mathrm{~S}$ ribosomes into $50 \mathrm{~S}$ and $30 \mathrm{~S}$ subunits.

(6) Effect of Monovalent Cations

In the previous paper ${ }^{11)}$, we suggested that the binding affinity of $E$. coli ribosomes
Table 3. Effect of components of poly A directed polylysine synthesizing system on the binding of erythromycin to ribosomes

\begin{tabular}{|c|c|}
\hline Addition of other components & $\begin{array}{l}{ }^{14} \mathrm{C} \text {-Erythromycin } \\
\text { bound }(\mathrm{cpm})\end{array}$ \\
\hline None & 1,005 \\
\hline tRNA & 1,032 \\
\hline$S-100$ & 980 \\
\hline Poly A & 1,015 \\
\hline $\begin{array}{l}\text { ATP, GTP, Phosphoenolpyru- } \\
\text { vate and pyruvate kinase }\end{array}$ & 1,029 \\
\hline 2-Mercaptoethanol & 1,001 \\
\hline $\begin{array}{l}\text { Each component added } \\
\text { together }\end{array}$ & 975 \\
\hline \multicolumn{2}{|c|}{$\begin{array}{l}\text { To the reaction mixture (containing } 2.8 \mathrm{~A}_{260} \text { units of } \\
\text { ribosomes) described under "Materials and Methods", } \\
\text { tRNA }(45 \mu \mathrm{g}), \mathrm{S}-100(80 \mu \mathrm{g} \text { protein), poly A }(10 \mu \mathrm{g}) \text {, ATP } \\
(0.375 \mu \mathrm{mole}), \mathrm{GTP}(0.0375 \mu \text { mole), phosphoenolpyruvate } \\
(1.25 \mu \mathrm{mole}), \text { pyruvate kinase }(3.75 \mu \mathrm{g}) \text { and } 2 \text {-mercapto- } \\
\text { ethanol }(1.25 \mu \text { mole) were added as indicated. }\end{array}$} \\
\hline
\end{tabular}

Fig. 3. Time course of the erythromycin binding to ribosomes.

The reactions were carried out as described under "Materials and Methods" except that incubations were carried out varying periods of time and at different temperatures as indicated. Incubation mixture contained $3.0 \mathrm{~A}_{260}$ units of ribosomes.

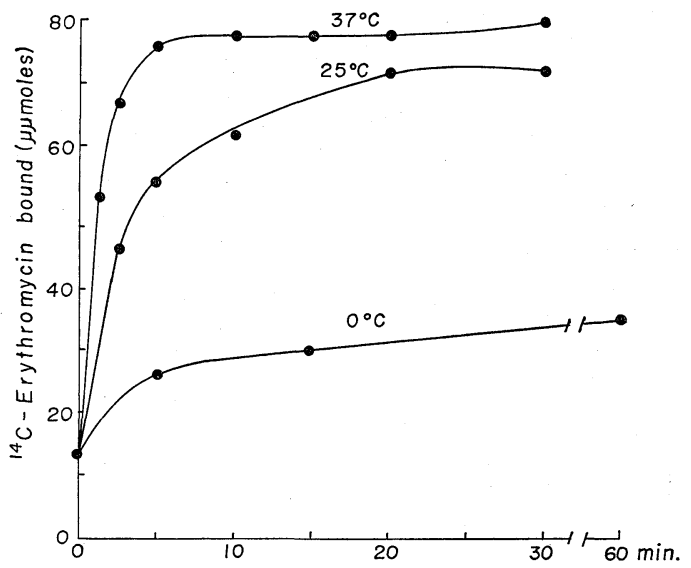


for erythromycin depends upon the ribosome conformation which is reversibly altered with changes in the concentration of $\mathrm{K}^{+}$or $\mathrm{NH}_{4}{ }^{+}$. As expected from the previous paper, the binding of erythromycin was strongly dependent upon the concentration of $\mathrm{K}^{+}$or $\mathrm{NH}_{4}{ }^{+}$. As shown in Fig. 4, the amounts of erythromycin bound to a fixed amount of ribosomes increased as the concentration of $\mathrm{K}^{+}$was raised, reaching a maximum at approximately $0.05 \mathrm{M} \mathrm{K}^{+}$in the presence of $1.4 \times 10^{-6} \mathrm{M}$ erythromycin. $\mathrm{NH}_{4}{ }^{+}$was a little more efficient than $\mathrm{K}^{+}$, the maximum binding of erythromycin being observed at approximately $0.03 \mathrm{M} \mathrm{NH}_{4}{ }^{+}$under the same conditions. At $0.02 \mathrm{M}$

Fig. 4. Effect of monovalent cations on the binding of erythromycin to ribosomes.

The reactions were carried out at varying concentrations of $\mathrm{K}^{+}, \mathrm{NH}_{4}{ }^{+}, \mathrm{Na}^{+}$or $\mathrm{Li}^{+}$in place of $0.07 \mathrm{M}$ $\mathrm{KCl}$ by the use of $2.8 \mathrm{~A}_{260}$ units of ribosomes. Other conditions were the same as described under "Materials and Methods".

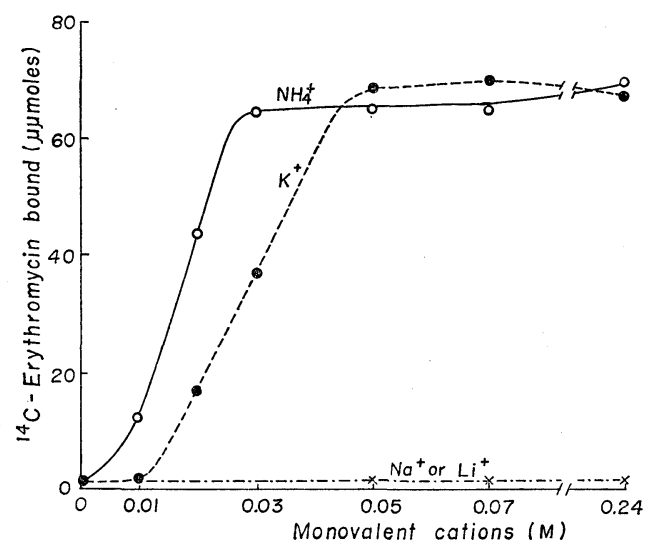

Fig. 5. Effect of $\mathrm{NH}_{4} \mathrm{Cl}$ washing on the erythromycin binding ability of ribosomes.

Ribosomes were preincubated at $37^{\circ} \mathrm{C}$ for 15 minutes in the buffer containing $0.24 \mathrm{M} \mathrm{NH}_{4} \mathrm{Cl}$ with other components of usual reaction mixture, then sedimented by centrifugation (at $105,000 \times g$ for 2 hours) through the buffer containing $0.24 \mathrm{M} \mathrm{NH}_{4} \mathrm{Cl}$ at $25^{\circ} \mathrm{C}$. The sedimented ribosomes were resuspended in tris-magnesium buffer containing $0.06 \mathrm{M} \mathrm{KCl}$. The erythromycin binding abilities of these $\mathrm{NH}_{4} \mathrm{Cl}$-washed ribosomes and non-treated control (2.8 $\mathrm{A}_{260}$ units of ribosomes respectively) were tested at various concentrations of $\mathrm{KCl}$ as described in Fig. 4.

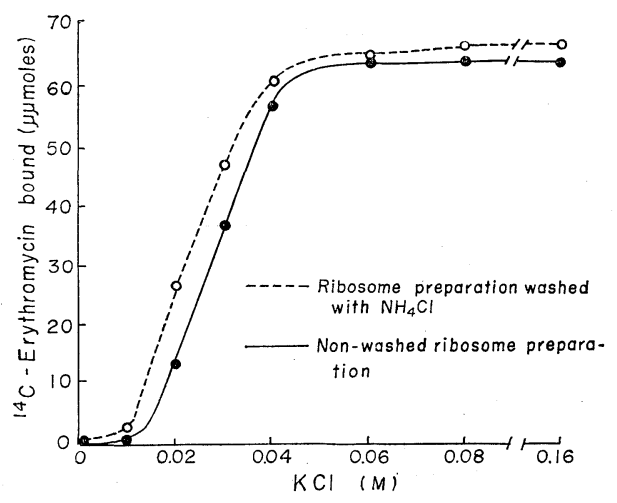

$\mathrm{KCl}$ where only a little binding of erythromycin was observed, the binding of erythromycin to ribosomes increased with the erythromycin concentration (Table 4). This fact supports the previous suggestion that

Table 4. Effect of erythromycin concentrations on the binding at low concentration of $\mathrm{KCl}$

\begin{tabular}{c|c|c}
\hline${ }^{14} \begin{array}{c}\text { C-Erythromycin } \\
\text { concentration } \\
(\mu \mathrm{M})\end{array}$ & \multicolumn{2}{|c}{${ }^{14}$ C-Erythromycin bound } \\
\cline { 2 - 3 }$(\mathrm{cpm})$ & $(\mu \mu \mathrm{mole})$ \\
\hline 0.66 & 93 & 6.0 \\
1.33 & 174 & 11.2 \\
3.3 & 366 & 23.7 \\
6.6 & 453 & 29.4 \\
13.3 & 661 & 42.9 \\
\hline
\end{tabular}

Incubation mixture contained $2.8 \mathrm{~A}_{260}$ units of ribosomes and the components described under "Materials and Methods" except that the concentration of $\mathrm{KCl}$ was decreased to $0.02 \mathrm{M}$ and various amounts of ${ }^{14} \mathrm{C}$-erythromycin were added as indicated.

Fig. 6. Inhibitory action of $\mathrm{Li}^{+}$on the binding of erythromycin and reversal of the inhibition by the concomitant addition of $\mathrm{NH}_{4}{ }^{+}$.

Incubation mixture contained indicated concentrations of $\mathrm{LiCl}$ with or without $0.4 \mathrm{M} \mathrm{NH} \mathrm{NH}_{4} \mathrm{Cl}$ in addition to the components (containing $3.2 \mathrm{~A}_{260}$ units of ribosomes) described under "Materials aud Methods".

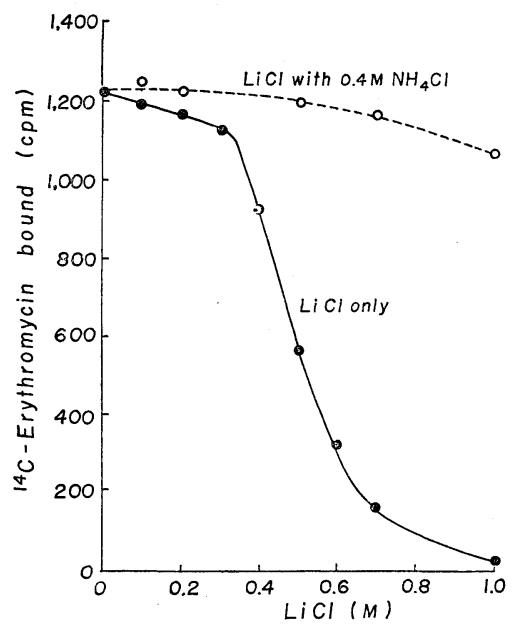


$\mathrm{K}^{+}$or $\mathrm{NH}_{4}{ }^{+}$induce a change in the affinity of ribosomes for the antibiotic.

To exclude the possibility that a factor which affects the affinity of ribosomes for erythromycin may be released from ribosomes at higher concentration of $\mathrm{K}^{+}$or $\mathrm{NH}_{4}{ }^{+}$, ribosomes were sedimented by ultarcentrifugation after the treatment with $\mathrm{NH}_{4} \mathrm{Cl}$ solution. The erythromycin binding capacity of these $\mathrm{NH}_{4} \mathrm{Cl}$-washed ribosomes was compared with that of non-treated ribosomes (Fig. 5). No detectable difference was observed between these two preparations in the final extent of binding and dependence on $\mathrm{K}^{+}$concentration.

As shown in Fig. 4, $\mathrm{Na}^{+}$or $\mathrm{Li}^{+}$could not replace $\mathrm{K}^{+}$or $\mathrm{NH}_{4}{ }^{+}$in enabling the binding of erythromycin to ribosomes, as was also the case in cell-free protein synthesis.

As shown in Fig. 6, the addition of $\mathrm{LiCl}$ showed a remarkable inhibition on the binding of erythromycin in the routine assay medium $(0.07 \mathrm{M} \mathrm{KCl})$. As indicated by the dotted line, however, this inhibition was almost completely reversed by the concomitant addition of $0.4 \mathrm{M} \mathrm{NH}_{4} \mathrm{Cl}$.

(7) Binding of Erythromycin to Ribosomes from B. subtilis and Rabbit Reticulocyte

It has been shown that $B$. subtilis, a strain of gram-positive bacteria, is hundreds times more sensitive to erythromycin than a gram-negative E. coli, and that the antibiotic shows little toxicity to mammals ${ }^{19)}$. It was therefore of interest to compare the erythromycin binding affinity of ribosomes from these different sources. By changing the concentration of $\mathrm{K}^{+}$or $\mathrm{NH}_{4}{ }^{+}$at a fixed concentration of erythromycin, the ability of these ribosomes to bind erythromycin was tested as described in the previous paper ${ }^{13)}$.

As shown in Fig. 7, the erythromycin binding affinity of ribosomes from B. subtilis was roughly the same as those from E. coli, while no detectable amount of the antibiotic was bound to rabbit reticulocyte ribosomes even at a high $\mathrm{NH}_{4}{ }^{+}$concentration where the maximum binding of erythromycin was observed with ribosomes from an erythromycin resistant E. coli mutant (QE201).

\section{Discussion}

As reported previously, addition of erythromycin to the polylysine synthesizing system of $E$. coli cell-free extract induced complete inhibition of the synthesis of highly polymerized polylysine and simultaneous accumulation of di-, tri-, and tetralysine ${ }^{2}$. This characteristic accumulation of small lysine peptides has been demonstrated to be due to 
the binding of erythromycin to ribosomes ${ }^{1,2)}$. Preliminary studies indicated that the binding of erythromycin to ribosomes was not interfered with by the concomitant addition of chloramphenicol and that the non-enzymatic binding of aminoacyl-tRNA to ribosomes was not inhibited by the binding of erythromycin ${ }^{4}$. It was further shown that lincomycin, which like chloramphenicol has been considered to act on $50 \mathrm{~S}$ ribosomal subunits, does not inhibit the binding of erythromycin to ribosomes ${ }^{20)}$. Much larger amounts of chloramphenicol and lincomycin were required to inhibit the poly A directed polylysine synthesis in E. coli cell-free system than that required for erythromycin and the accumulation of large amounts of small lysine peptides was not observed even when excessive amounts of chloramphenicol or lincomycin were added to the E. coli cell-free system of polylysine synthesis ${ }^{20)}$. Considered together with the results in Fig. 2, these facts suggest that erythromycin, in comparison with chloramphenicol or lincomycin, binds much more tightly to a specific site of $E$. coli ribosomes and induces highly specific changes in the abilities of the ribosomes.

It was suggested in a previous paper that the affinity of $E$. coli ribosomes for erythromycin depends upon the ribosome conformation, which is reversibly altered with changes in the concentration of $\mathrm{K}^{+}$or $\mathrm{NH}_{4}{ }^{+11)}$. As shown in Fig. $5, \mathrm{NH}_{4} \mathrm{Cl}$-washing of ribosomes did not alter their ability to bind erythromycin. Since $\mathrm{LiCl}$ has been considered to induce alterations of ribosome structure ${ }^{21}$, the inhibition of the erythromycin binding caused by $\mathrm{LiCl}$ may be due to alteration of the ribosome structure. Our previous report suggested that the presence of $\mathrm{K}^{+}$or $\mathrm{NH}_{4}{ }^{+}$may not always be necessary for the binding of erythromycin but that these monovalent cations may have an important role in the regulation of the conformational changes of ribosomes ${ }^{11}$. Therefore, the observation that the inhibition by $\mathrm{LiCl}$ of the binding of erythromycin to ribosomes was reversed by the concomitant addition of $\mathrm{NH}_{4} \mathrm{Cl}$ may indicate that $\mathrm{NH}_{4}{ }^{+}$prevents the alteration of ribosome structure by $\mathrm{LiCl}$ which reduces the erythromycin binding ability of ribosomes. It is interesting to note that $\mathrm{K}^{+}$or $\mathrm{NH}_{4}^{+}$, indispensable for polypeptide synthesis, was also essential for the binding of erythromycin to ribosomes, while $\mathrm{Na}^{+}$and $\mathrm{Li}^{+}$were inactive in the binding as they are in polypeptide synthesis. Erythromycin bound exclusively to $50 \mathrm{~S}$ ribosomal subunits and this binding was not affected at all by the presence of $30 \mathrm{~S}$ subunits. This may indicate that $30 \mathrm{~S}$ ribosomal subunits do not have a significant effect on the conformational change of $50 \mathrm{~S}$ subunits.

Erythromycin is highly active against gram-positive bacteria compared with gramnegative bacteria. As shown in Fig. 7, however, the ribosomes prepared from these two bacterial groups seem to have roughly the same ability to bind erythromycin. Hence the difference in susceptibility to erythromycin of gram-positive and gram-negative bacteria may be due to a difference in some factor(s) other than ribosomes, possibly in the permeability of their cells to the antibiotic. It is also evident in Fig. 7 that erythromycin is scarcely bound to reticulocyte ribosomes even under conditions where the maximum amount of the antibiotic binds to the ribosomes from a highly erythromycin resistant mutant of E. coli. This result is in harmony with the fact that erythromycin exhibits very low toxicity to mammals, suggesting that there are great differences in the conformation of ribosomes of bacteria and mammals.

Acknowledgement

The author wishes to acknowledge Dr. K. TANAKA for his helpful advices and encouragement throughout this work. Thanks are also due to Mr. S. Watanabe and Mr. M. Tamaki for their assistance.

\section{References}

1) Tanaka, K. \& H. Teraoka : Binding of erythromycin to Escherichia coli ribosomes. Biochim. Biophys. Acta $114: 204 \sim 206,1966$ 
2) Tanaka, K. \& H. Teraoka : Effect of erythromycin on polylysine synthesis directed by polyadenylic acid in an Escherichia coli cell-free system. J. Biochem. $64: 635 \sim 648,1968$

3) Tanaka, K.; H. Teraoka, T. Nagira \& M. TAmaki : Formation of ${ }^{14}$ C-erythromycin-ribosome complex. J. Biochem. $59: 632 \sim 634,1966$

4) Tanaka, K.; H. Teraoka, T. Nagira \& M. Tamaki: ${ }^{14}$ C-Erythromycin-ribosome complex formation and non-enzymatic binding of aminoacyl-transfer RNA to ribosome-messenger RNA complex. Biochim. Biophys. Acta $123: 435 \sim 437,1966$

5) Taubman, S. B.; N. R. Jones, F. E. Young \& J. W. Corcoran : Sensitivity and resistance to erythromycin in Bacillus subtilis 168 : the ribosomal binding of erythromycin and chloramphenicol. Biochim. Biophys. Acta $123: 438 \sim 440,1966$

6) MaO, J. C.-H. : The stoichiometry of erythromycin binding to ribosomal particles of Staphylococcus aureus. Biochem. Pharmacol. $16: 2441-2443,1967$

7) Tanaka, K.; H. Teraoka, M. Tamaki, E. Otaka \& S. Osawa : Erythromycin-resistant mutant of Escherichia coli with altered ribosomal protein component. Science $162: 576 \sim 578,1968$

8) Tanaka, K.; H. Teraoka, M. Tamaki, E. Otaka \& S. Osawa: Studies on ribosomes from erythromycin-resistant mutants of Escherichia coli with altered ribosomal protein component. Progress in Antimicrobial and Anticancer Chemotherapy, Vol. II, pp. 499 501, University of Tokyo Press, Tokyo, 1970

9) Oleinick, N. L. \& J. W. Corcoran: Two types of binding of erythromycin to ribosomes from antibiotic-sensitive and -resistant Bacillus subtilis 168. J. Biol. Chem. $244: 727 \sim 735,1969$

10) Mao, J. C.-H. \& M. Putterman: The intermolecular complex of erythromycin and ribosome. J. Mol. Biol. $44: 347 \sim 361,1969$

11) Teraoka, H.: A reversible change in the ability of Escherichia coli ribosomes to bind to erythromycin. J. Mol. Biol. $48: 511 \sim 515,1970$

12) Nirenberg, M. W. : Cell-free protein synthesis directed by messenger RNA. Methods in Enzymology, Vol. VI, ed. by S. P. Colowick and N. O. Kaplan, pp. 17 23, Academic Press, New York, 1963

13) Otaka, E.; H. Teraoka, M. Tamaki, K. Tanaka \& S. Osawa: Ribosomes from erythromycinresistant mutants of Escherichia coli Q13. J. Mol. Biol. 48: 499 510, 1970

14) Tanaka, K.; S. Watanabe \& M. Tamaki : Mode of action of siomycin. J. Antibiotics $23: 13$ $\sim 19,1970$

15) Tissieres, A.; J. D. Watson, D. Schlessinger \& B. R. Hollingworth : Ribonucleoprotein particles: form Escherichia coli. J. Mol. Biol. $1: 221 \sim 233,1959$

16) Kaneda, T.; J. C. Butte, S. B. Taubman \& J. W. Corcoran: Actinomycete antibiotics. III. The biogenesis of erythronolide, the $\mathrm{C}_{21}$ branched chain lactone in erythromycin. J. Biol. Chem. $237: 322 \sim 328,1962$

17) Wilhelm, J. M.; N. L. Oleinick \& J. W. Corcoran: Interaction of antibiotics with ribosomes : Structure-function relationships and a possible common mechanism for the antibacterial action. of the macrolides and lincomycin. Antimicr. Agents \& Chemoth.-1967:236 250, 1968

18) Conmay, T. W.: On the role of ammonium or potassium ion in amino acid polymerization. Proc. Natl. Acad. Sci., U. S. A. 51 : 1216 1220, 1964

19) HaHN, F. E. : Erythromycin and oleandomycin. Antibiotics, Vol. I : Mechanism of action. ed. by D. Gottlieb and P. D. Shaw, pp. 378 386, Springer-Verlag, New York, 1967

20) TeraOKa, H.; K. TANAKa \& M. TAMaKi: The comparative study on the effects of chloramphenicol, erythromycin and lincomycin on polylysine synthesis in an Escherichia coli cell-free system. Biochim. Biophys. Acta $174: 776 \sim 778,1969$

21) KAJI, A. \& H. K $\mathrm{AJI}$ : Specific interaction of s-RNA with polysomes: Inhibition by LiC1. Biochim. Biophys. Acta $87: 519 \sim 522,1964$ 